\title{
A Comprehensive Study on Effective Administration of University Leadership and Limitations
}

\author{
Mohammad Golam Moula
}

\begin{abstract}
University leadership means the overall state of the administrative structure of a university which many universities in Bangladesh and the world have failed to meet this demand. In this paper, the researcher goes on to show how effective authority of a university can be built and the survey further shows how important effective authority of a university. University leadership and administration is a serious characteristic as it is about the effective of the whole institution. Leading promoters encourage transformational leadership, moral stewardship, principal as an instructional leader, and principal as a communicator or community builder. Effective and capable administration of the university relies on the principal. Leadership effectiveness is more related to situational leadership style in research universities and in a global framework. Hence, training and advance in university leadership involves a systematic planning which will result to outstanding institution.
\end{abstract}

Keywords: University Leadership, Leadership Styles, Administration, Training, Efficient, Effective.

\section{INTRODUCTION}

\section{A}

dministrative leadership is like the paired elements that form the genetic material helix. They are in a continuous connection to each other, distinct but connected. The most qualified administration cannot be effective in their effort with progenies and peoples if their work situations with administrator support, chances for qualified progress, decision creating, collegiality, prizes and acknowledgment, character clearness, career direction, innovativeness, and corporeal atmosphere do not sufficiently provision them. Administrative leadership is significant because without it, instructive leadership cannot be continued. The achievement of an institute is mainly strong-minded by the efficiency and competence of its administration. Now a day's leaders need to identify new awareness, capacities and skills to efficiently manage with the perpetual organizational modifications. Effectiveness is alarmed with 'doing thing right', while efficiency is alarmed with 'doing the right things'. All in all attractive strategy should form reasonable advantage; progresses administrative performance; meets the opportunities of investor; and bring into line itself with environmental condition. Usefulness is connected with considered administration while proficiency is related to working management.

Manuscript received on March 09,2021

Revised Manuscript received on March 15,2021

Manuscript published on March 30, 2021.

* Correspondence Author

Mohammad Golam Moula*, Administrative Management and Statistical Survey, Bangladesh.

(C) The Authors. Published by Blue Eyes Intelligence Engineering and Sciences Publication (BEIESP). This is an open access article under the CC BY-NC-ND license (http://creativecommons.org/licenses/by-nc-nd/4.0/)

In all-purpose, administration may be said to emphasis more on the duty, and leadership more on the people. However, since administration generally contains the leadership procedure or does, at least, similarity with leadership courses, the term 'management' will be used to include the leadership measurement. One may, for the sake of simplicity, refer to executive leadership which would denote that the administrator has to lead as well as angement and reserve the institute to complete declared the work done through others. This could be a different method to view the administration procedure, since this indicates a part of leadership. In the framework of this paper, administrative conduct includes the single group's announcement, contacts, nation, organization and project with administration and leadership located at the center. This should not be misread to mean that administrator and chosen are the essential figures in administrative life. They may use genuine influence through their position in the institute, but without the services and proficiency of others and without the important part played by the client they would have no part to show at all. But it is possibly true to say that they have more inspiration on all the sizes than anyone else. This effect could be a positive or a negative one. This inspiration may be used very ultimately, but it is usually there in some procedure. This is, after all, why they are salaried more than others and are held responsible to the monetary sponsor when the institute is ineffective. Employing them at the midpoint means that administrators are both the yields and agents of deviations and doings in the institute. They are not stand-up external the institute. They are quantity of the tricky as well as quantity of the clarification.

of administrators and leaders is to:

(b) Accomplish themselves and their replies

(c) Achieve all the administrations and procedures

(d) Bring about the control they have and how they work out this control in exercise.

This does not unpleasant that they will ensure the whole thing themselves. Undoubtedly administrators have to representative and prepare others to acquire the work done. But this does not release them from the career of working and being responsible for the consequences. Administrators have to be conscious of and measure positions both private and external institution. 
These earnings that their individual observations have an energetic part to play in their administration work. In considering and taking conditions, the administrators cannot risk taking a thin view. They have to administrator their intellectual and the method they communicate to and connect with others.

\section{LITERATURE REVIEW}

In 2007, the selected HEI appointed a new Council, new Vice-Chancellor and new Deputy Vice-Chancellor: Academic. At the end of that year the HEI consolidated the merger and rounded it off, and in 2008 it embarked on the major mission of its young life: transforming into a University of Technology, not just in name, but in practice. The selected HEI faced many challenges regarding its plans and efforts to refocus itself as a new type of university. While the two constituent institutions had been similar institutional types that is, technicians, they had had different cultures and artifacts in relation to academic and religious backgrounds and to their distinguishing colors and symbols. This had been a bedeviling factor during the merger process, which sought to create a cohesive and settled university community (Durban University of Technology Annual Review Report, 2009:34) [4]. Elham Shahmandi, Abu Daud Silong, Ismi Arif Ismail, Bahaman Bin Abu Samah and Jamilah Othman have proposed Competencies, Roles and Effective Academic Leadership in World Class University in their research [1]. In this paper they have shown different activities for good leadership of world Class University.Spendlove (2007) asserted, over the past ten years research in leadership effectiveness has moved towards identifying the leadership competencies such as knowledge, skills, abilities and behaviors of individuals. Also, Spendlove (2007) mentioned that, competencies are defined as sets of behaviors that are instrumental in the delivery of desired results or Outcomes [2]. D. Goleman, R. Boyatzis and A. McKee (2002) have shown Primal leadership. In their research they have discussed about realizing the power of emotional intelligence [3]. Bartram (2005) explained that the competencies are more difficult to learn than others (Tubbs and Schultz, 2005), however defining specific competencies can guide strategic human resource management practices in areas such as in recruitment and succession planning. Competencies and roles, offer a useful tool for leadership effectiveness.Knowledge Ngwane and Cabangile Ngwane have described about Effective Administration of University Leadership in a Selected Institution in Durban. The principle of effective administration of University Leadership has explained in this article [5].

\section{THE OBJECTIVES OF THE STUDY}

\section{Broad Objective:}

- The main purpose of this study is to conclude why administration leadership more effective and objectives of the experiential investigation of this research are to study and discover the actual causes of the weakness in administration leadership at all level and to analyze them in order to find out the solution

- An experimental investigation of the likings and disliking of management; beliefs, mentalities, experiences, achievements of the universities administration, attitudes of stuff, leadership learning environments, and techniques, were considered as all these factors are related. The results of the discovery can change the leadership learning situation positively and management can be successful in learning and remove weakness of effective administration leadership.

\section{Specific Objectives:}

* To know how an administration leadership can become more effective?

* To justify the actual reason of the weakness in administration leadership

* To analyze management quality and proper weakness on Leadership.

\section{Research questions}

* What are the main reasons on administration leadership?

* Why do they fail to take proper decision timely?

* How does it influence their learning and result?

\section{METHODOLOGY}

The methodology of this article is mainly descriptive. In this paper, the researcher has been adopted mainly the desk study method to search the different aspects of effective administration. It is based on the evaluation of the published and unpublished literatures from different sources including worldwide web. Different recent articles and the research report related to the effective administration were reviewed thoroughly to describe the different aspects of effective administration. The related books on theory of effective administration are also reviewed to some extent. Apart from this four main techniques of the survey method

* Questionnaire survey from various universities Vice Chancellor

* Interview from various universities Treasure and Registrar

* Observation of Management leadership mentality

* Opinion from administrative trainer

Types of research and elements: The types of research are descriptive. To investigate into a problem or situation this provides insights to the researcher. The research is meant to provide details where a small amount of information exists. It may use a variety of methods such as trial studies, interviews, experiments or other tactics for the purpose of gaining information. The elements of this research are Vice Chancellor/ Treasurer/ Registrar/ Leadership Trainer and higher authority for selected institution.

\section{ADMINISTRATIVE LEADERSHIP}

Administrative leadership is about arranging responsibilities to advance and tolerate an early childhood institute. Successful administrative leaders are intelligent to establish methods that protect and tolerate essential working functions to meet the needs of children and peoples. There are at least two important aspects of administrative leadership are effective leadership and planned leadership. 
Effective leadership is proficient through activities like engagement and associate staff, administration budgets, and maintaining a positive workplace environment. Planned leadership involves administrative the direction of an early childhood institute with the future in mind. Planned leaders explain purpose, inspire individuals to pursue a shared idea, and ensure that objectives and conclusions are attained. I actually like this explanation for a pair of motives.

First, it types it clear that arranging the work of instruction and knowledge, organizing staff to realize youth and platform results, and beginning systems to successfully run a healthy, flourishing institute are indeed leadership purposes. In our field of initial attention and learning, these responsibilities are classically considered as administration purposes and are less appreciated than leadership purposes.

\section{WORLDWIDE UNIVERSITIES LEADERSHIP}

World-class universities are related with the top universities in the several countries abroad. Asia is area of variety in many sides, namely the physical, socio-financial and administrative status, the history of effective administration and the national strategies and Asian countries are in different periods of national improvement. Higher education/effective administration in Asian countries at present is a new classification taken into the area only in the last century. The organization and purposes of universities are introduced. It is believed that such opinion has helped mankind in the development and improvement of social culture and well-being. It is closely linked with government and administrative system in the countries, as well as with the organization and purposes of the effective administration. Acknowledgement and understanding of these roles be different. Moreover, Effective administration system in the area is facing new challenges, namely basification, limitation of resources, corporatization and transfer, globalization, evidence and communication knowledge's as well as information-determined economy and awareness based society. Investigative an administration's method to leadership from the past to the future in Asian academic organizations shows that a effort from more separate methods to those that are more collective process to leadership.

\section{EFFECTIVE ADMINISTRATION LEADERSHIP}

Actual leadership delivers a central sense of way and idea, a position with the environment, a strong instrument for invention and inspiration and a source for refreshing the administrative nation. With effective leadership, cases of corruption can be reduced in the public sector.

The principles of leadership rests on three stakes: firstly, the ethical personality of the leader, secondly, the proper values implanted in the leader's idea and speech thereof and lastly, the standards of the selections and activities that leaders and followers involve in and follow to recognize the proper idea. Immoral activities are therefore not thoughtless; it is a premeditated performance, which highlights the importance and control of complete moral personal values for avoiding immoral leadership. Effective leadership delivers higher-class and more effective properties and facilities. It delivers a sense of cohesiveness, personal growth and higher levels of gratification among those leading the work.

Immoral leadership in the community facility contains dishonesty, lack of awareness to the needs of consumers, delay in the release of duties and appearances of incompetence and ineffectiveness. However, for the purpose of this article, effective leadership will be the only focus. Effective leadership frequently starts at the top of the organization, where institutes values are not personified and encouraged.

i) Methods to Leadership: In this article a short-term summary of some of the main universities of believed about leadership will be deliberated. The research will evaluation and increase on these different methods and for the sake of investigative a wide choice of views, type a brief difference between concepts of leadership and concepts of administration.

ii) Leadership procedures: Moral leadership is a purpose of good administration and leadership systems. It doesn't matter very much how good the leaders are. If they have good and well verified classifications which they can learn to use, the organizations can do most of the leadership job for them.

iii) Leadership facilities: Decent leaders have specific communication services in intelligent and behavior people, and are either natural with these services or attain them. This works well as long as leaders can apply these general services in the hurly of real life circumstances.

iv) Leadership types: Virtuous leaders have self-confident basic faces for successful leadership such as understanding, resolve and empathy and pressure tolerance. Inopportunely, slight contract can be reached on the universality of these characters other than very general characters like thought for others and having a wide perception.

v) Team leadership: Respectable leadership only exits in well equilibrium teams. No one person can lead; it is always a team determination where each person has a specific role to play on the supposition that the team is always better than the separate leader. This is true in many circumstances, but there are times when the strong magnetic up-front leader can save the day.

vi) Leadership Roles: As the leader involves with characters within and outside the organization, his or her role requirements will be constantly shifting in accordance with the demands and desires of peers, subordinates and superiors. Much of the modern management theory today relies heavily upon previous work. Many researchers has been shown that view of leadership behavior complements various organizational behavior theories, and stressing the motivation of the individual, proper communication, leadership and decision making and observed that managerial work encompasses various roles, which is grouped into three major categories.

vii) Decision making: It involves of the characters of businessperson, trouble trainer, supply allocator and representative. The financier projects and initiates administrative modification and the trouble handler switch problems ascending from administrative struggle and disturbance. 


\section{A Comprehensive Study on Effective Administration of University Leadership and Limitations}

As a resource allocator, the leader panels and schedules the allocation of personnel, time and financial resources. As a negotiator the leader represents the organization in both external and internal negotiations.

viii) Data processing: It contains the roles of display, disseminator and representative. In the display part, the leader gathers data both outside and interior to the institute. As a disseminator, the leader allocates data to subordinates through formal and informal means. Acting as a representative, the leader gives information to those outdoor the institute.

ix) Interactive connection: In this group, the roles of figurehead, leader and link make up the social contact group. As a figurehead, the leader represents and signifies the institute by performing formal responsibilities. In the role of leader, he cooperates with groups and also supports, inspires and develops supporters. In the roles of a link, the leader founds formal and informal systems to gain data serious to the success of the institute.

\section{FINDINGS BASED ON SERVEY}

Researcher has surveyed on Vice Chancellor/ Treasurer/ Registrar/ Leadership Trainer where total number of populations is 150 and sample size is 100 by randomly. University: Vice Chancellor: 10, Treasurer: 15, Registrar: 20, Leadership Trainer: 55.

i) Teacher, MLSS and management close relationship are the main causes of administrative limitation

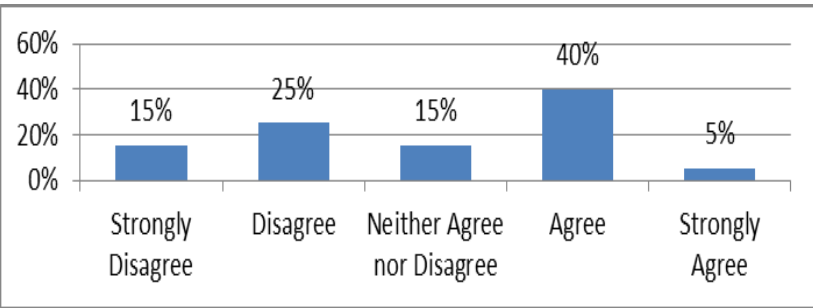

ii) One of the reasons for the limitations in the administration is the lack of service rules

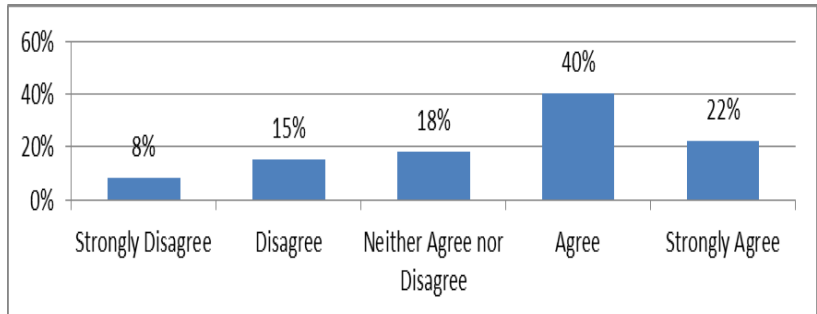

iii) Lack of more effective decision is the vital reason of administrative limitations

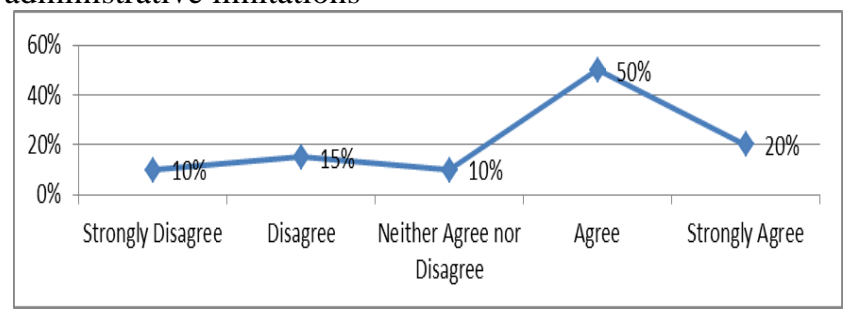

iv) As usual decision makes the gap between teacher and administration.

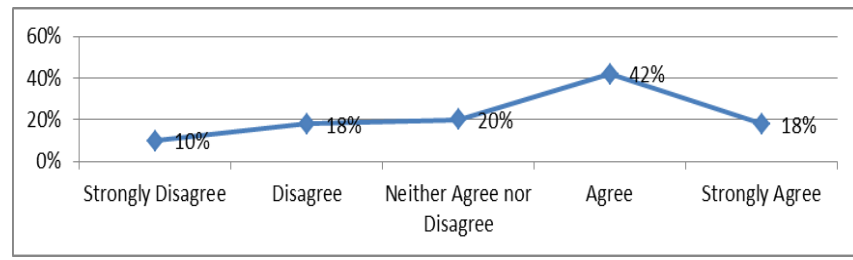

v) Negative attitude towards administration makes the difficulties to solve the problems

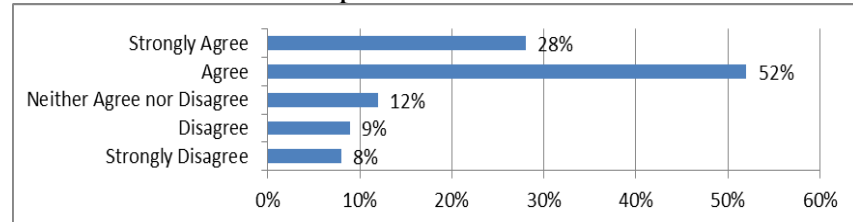

vi) One of the aspects of administrative failure is the lack of increase in the number of students in the university

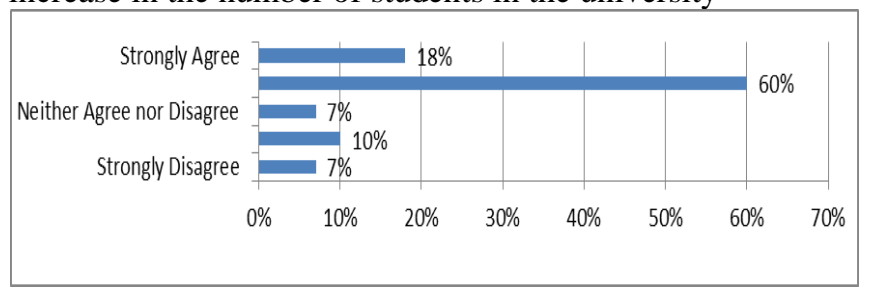

The probable solution to overcome Leadership problems

As it is well known that there is Vice Chancellor/ Treasurer/ Registrar/ Leadership Trainer for the success of effective administration, the role of each is important to solve problems from administration. What administration can do? A very important factor in motivating stuff to study effective administration is that the stuff stays positive and enthusiastic about effective management.

Researcher has found by his study some of the remedies how to overcome the math fear or phobia are given below.

- Avoid to compare the stuff abilities to others

- Increase the use of instructional materials.

- Emphasize the admin stuff's sense of intelligence and skill in management learning

- Encourage the stuff to tackle in direction

- Explain everyone about positive uses of decision

- Use of modern facilities, devices, and tools

- Create a helpful environment for learning

- Use of innovative and contemporary approaches

- Develop and maintain close stuff relationship

- Use of ICT in teaching learning situation

- Make enough and effective practice of administration

\section{CONCLUSION}

In this research, Researcher has planned and experimental some issues related to the effective administration by stuffs at all level in Bangladesh. In adding, Researcher also tried to learn about effective management methods, earning materials, environment situations, learner's expectations, management's expectations and a few other things related to them. Researcher believes that if the administration just follows the planning, effective administration would be overcome. So, administration needs to understand the causes and effects of effective management as well as the ways to help management to overcome it.

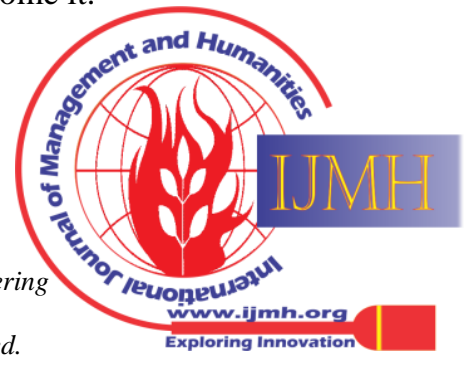




\section{REFERENCES}

1. Shahmandi, E., Silong, A. D., Ismail, I. A., Samah, B. B. A., \& Othman, J. (2011). Competencies, roles and effective academic leadership in world class university. International Journal of Business Administration, 2(1), 44-53.

2. Spendlove .M. (2007). Competencies for effective leadership in higher education. International Journal of Educational Management. Aston University, Birmingham, UK . 21(5) pp 407- 417

3. Goleman, D., Boyatzis, R., \& McKee, A. (2002). Primal leadership: Realizing the power of emotional intelligence. Boston: Harvard Business School Press.

4. Durban University of Technology, 2009. Annual Review Report.

5. Ngwane, K. S. V., \& Ngwane, C. N. (2015). Effective administration of university leadership in a selected institution in Durban. ICERI proceedings (Internet).

6. Louw, L. and Venter, P. (2013). Strategic Management: Developing sustainability in Southern Africa. 3rd ed. Cape Town: Oxford University Press.

7. Misselhorn, H. (2005). Understanding and Managing your organisation. MOD Consulting: Durban.

8. Durban University of Technology, 2009. Annual Review Report.

9. Durban University of Technology, 2015. Strategic Plan.

10. Mafunisa, M.J. (2008). The role of codes of conduct in promoting ethical conduct in the SA public service. SA Journal of Labour Relations 32(1). pp81-92.

11. Anderson, T.D. (1992). Transformational leadership: new skills for an extraordinary future. Massachussets: Human Resource Development

12. https://mccormickcenter.nl.edu/library/administrative-leadership-what -is-it-why-is-it-important/

\section{AUTHORS PROFILE}

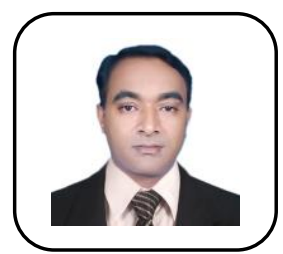

Mohammad Golam Moula, Research field: Administrative Management and Statistical Survey. Masters of Commerce (Management) Bachelor of Commerce (Management)

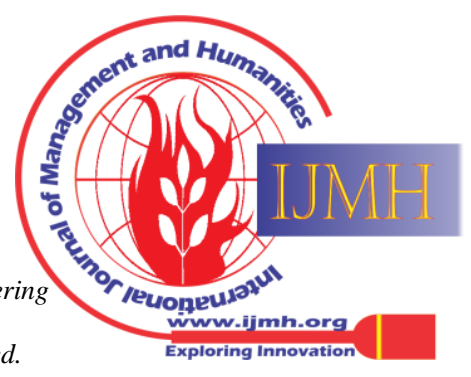

